\title{
CORROSION INHIBITION STUDIES OF 3- [(METHACRYLOYLAMINO) PROPYL] TRIMETHYLAMMONIUM CHLORIDE AND N-SUBSTITUTED ACRYLAMIDE IONOMERS
}

\author{
V. Swarnalatha ${ }^{1}$ and P. Pazhanisamy ${ }^{2}$ ** \\ ${ }^{1}$ Research and Development Centre, Bharathiar University, \\ Coimbatore-641046, Tamil Nadu, India \\ ${ }^{2}$ Department of Chemistry, Sir Theagaraya College, Chennai-600021, Tamil Nadu, India \\ E-mail: p_pazhanisamy@yahoo.com
}

\begin{abstract}
Free radical copolymerization of MPTMACl with N-substituted acrylamide was carried out in aqueous methanol using ACVA as an initiator. Since MPTMACl monomer was in the form of an aqueous solution (50\%) and the Nsubstituted acrylamides are insoluble in water, methanol/water (3:1) medium was used for copolymerization. The synthesized copolymers(ionomers) are characterized by ${ }^{13} \mathrm{C}$-NMR, SEM, TGA analysis. The inhibition effect of ionomers on the mild steel in $3.5 \% \mathrm{NaCl}$ solution was studied by potentiodynamic polarization curves and electrochemical impedance spectroscopy (EIS) methods. NCA based Ionomers showed a maximum of 99\% inhibition efficiency. The antifouling study was carried out in sea water for a period of six months.

Keywords: corrosion, thermal analysis, nanosize , ionomers, spectroscopy, antifouling
\end{abstract}

(C) RASĀYAN. All rights reserved

\section{INTRODUCTION}

Steel is used as constructional material in all field of industries because of low cost. The major problem of steel is its dissolution in the acidic and alkaline medium. Corrosion of iron and steel in acidic aqueous solutions is one of the major areas of concern in many industries wherein acids are widely used for applications such as acid pickling, acid cleaning, acid descaling, and oil well acidizing. Because of the general aggressiveness of acid solution, the materials of construction are being corroded easily. It is necessary to add corrosion inhibitors to prevent metal dissolution and minimize acid consumption ${ }^{1-8}$. Most well-known acid inhibitors are organic compounds containing nitrogen, sulphur and oxygen atoms. The inhibiting action exercised by organic compounds on the dissolution of metallic species is normally related to interactions by adsorption between the inhibitors and the metal surface. The good inhibitor has many advantages such as high inhibition efficiency, low price, low toxicity and easy production ${ }^{8}$. In the last two decades, there has been an increase in the use of a polymeric compound as corrosion inhibitors. The practical methods available for the protection of metals against corrosion are diverse. These may be divided into the following groups viz., (a) selection of metals (b) modification of metal (c) change in design (d) change in corrosive environment (e) surface coatings (f) change of the electrode potential of metal/corrosive medium. The most commonly practiced methods of control are changing the environment. An inhibitor is a chemical compound that effectively reduces the corrosion rate of a metal when added in small concentration to a mildly aggressive medium or environment ${ }^{8}$. This acts by changing the surface or both depending on the individual system. Electrochemical corrosion involves two partial reactions, one at the anode and another at the cathode. Polymers, copolymers, grafted polymers and polymer composites are used as corrosion inhibitors. Umoren ${ }^{9,10}$ discussed the corrosion prevention using polymeric compounds.

Rasayan J. Chem., 11(3), 929-934(2018)

http://dx.doi.org/10.31788/RJC.2018.1132073

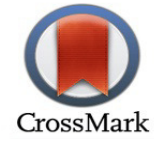


RASĀYAN J. Chem.

Vol. 11 | No. 3 |929 - 934 | July - September | 2018

The main controlling factors influencing the corrosion inhibitive performance of polymeric compounds on the corrosion of metals in various corrosive environments have been discussed.

The main factors influencing the corrosion mitigating properties of the polymers are molecular size, weight, composition and nature of the anchoring groups. The solution $\mathrm{pH}$, concentration, exposure time and temperature also find their role in influencing the inhibition performance. Polymeric quaternary ammonium compounds having unique properties attracted great attention to apply as anti-corrosive materials in various industrial processing for preventing corrosion of iron and steel in acidic media ${ }^{\mathbf{1 1}}$.The present study describes, the preparation, spectral characterization, thermal behavior, antimicrobial activity, potentiodynamic polarization and antifouling of Methacrylamido propyltrimethylammonium chloride(MPTMACl) and $\mathrm{N}$-substituted acrylamides copolymers. To evaluate the corrosion protection properties of these copolymers, potentiodynamic polarization study was carried out with mild steel samples dip coated with different compositions of the copolymers in $3.5 \% \mathrm{NaCl}$. Moreover, the mild steel specimens coated with copolymer were used for the antifouling study.

\section{EXPERIMENTAL}

The monomers N-tert-amylacrylamide (NTA), N-tert-butylacrylamide (NTB) and Ncyclohexylacrylamide (NCA) were prepared by a procedure described in literature ${ }^{\mathbf{1 2}}$. A solution containing $2.5 \mathrm{~g}(0.18 \mathrm{~mol})$ of NTA, $1.25 \mathrm{~g}(0.0057 \mathrm{~mol})$ of MPTMACl and $0.1 \mathrm{~g}(0.0071 \mathrm{~mol})$ of ACVA in $50 \mathrm{ml}$ of 3:1 methanol/ water medium was placed in a polymerization tube. The solution was flushed with oxygen-free dry nitrogen gas for about $30 \mathrm{~min}$ and polymerization tube was closed by means of rubber tubing with pinch cock. The tube was then placed in a thermostatic water bath at $55 \pm 1{ }^{\circ} \mathrm{C}$. After 12 $\mathrm{h}$ the reaction solution obtained was poured into ice-cold water and the copolymer precipitated by adding an electrolyte .The precipitated polymer was washed with benzene to remove the unreacted monomer. The other ionomers of MPTMACl-NTB and MPTMACl-NCA were also prepared similarly. The ${ }^{13} \mathrm{C}$-NMR spectrum of the copolymer was recorded on the GSX-400 spectrometer (JEOL, Tokyo, Japan) operating at $400 \mathrm{MHz}$ in $\mathrm{DMSO}\left(-d_{6}\right)$. Thermogravimetric analysis was carried out using TGA7 at a heating rate of $20^{\circ} \mathrm{C} / \mathrm{min}$ under nitrogen atmosphere. The copolymer samples were coated with a thin layer of gold by vaporization and morphology of polymers were observed by scanning electron microscope (LEO 1455VP).Mild steel specimens (Fe: 98.7; C: 0.033; Mn: 0.235; Si: 0.005; S: 0.005, etc.) of dimension $2 \mathrm{~cm} \times 1 \mathrm{~cm}$ were polished to a mirror finish, degreased with acetone and alcohol followed by double distilled water, and used for the surface examination studies. The specimens were kept in the desiccators for conditioning ${ }^{\mathbf{1 3}}$. Coatings were applied by hand bar coater on commercially available mild steel plates. The thickness of the coatings was found to be approximately $\pm 100 \mu \mathrm{m}$. The electrodes of $1 \mathrm{~cm}^{2}$ area were cut from the mild steel sheet and one side of the electrode and stem was masked with the polymer. The electrode was polished with 400-1200 grit emery papers and degreased with acetone. 100 $\mathrm{ml}$ of the test solution was taken in a three-electrode polarization cell and the electrode was introduced into the test solution in the polarization cell and allowed to attain a steady potential value for $20 \mathrm{~min}$. A constant potential was applied and the resultant current was measured. The experiments were carried out $\pm 200 \mathrm{mV}$ from corrosion potential. Polarization measurements were carried out using electrochemical workstation CHI 660 USA. The inhibition efficiency of these systems was calculated by using the following equation:

$$
\begin{aligned}
\mathrm{IE} \% & =\frac{\mathrm{I}_{\text {corr }}-\mathrm{I}_{\text {corr(i) }}}{\mathrm{I}_{\text {corr }}} \times 100 \\
\mathrm{I}_{\text {corr }} & =\text { Corrosion current density in the absence of inhibitor } \\
\mathrm{I}_{\text {corr(i) }}= & \text { Corrosion current density in the presence of inhibitor. }
\end{aligned}
$$

The EIS study was carried out using electrochemical work station CHI 660 USA. The real and imaginary parts of the impedance were plotted in the form of Nyquist plots. From the Nyquist plot, the charge transfer resistance $\left(\mathrm{R}_{\mathrm{ct}}\right)$ and double layer capacitance $\left(\mathrm{C}_{\mathrm{dl}}\right)$ values were calculated.The charge transfer resistance values were obtained from the plots of $Z^{\prime}$ vs $Z$ '. The values of $\left(R_{s}+R_{c t}\right)$ correspond to the point where the plots cuts $Z^{\prime}$ axis at low frequency and $R_{s}$ corresponds to the point where the plot cuts $Z^{\prime}$ 
axis at high frequency. The difference between $R_{c t}$ and $R_{s}$ values give the charge transfer resistance $\left(R_{c t}\right)$ values. The $\mathrm{C}_{\mathrm{dl}}$ values were obtained from the relationship:

$$
\mathrm{C}_{\mathrm{dl}}=\frac{1}{2 \pi \mathrm{f}_{\max } \times \mathrm{R}_{\mathrm{ct}}}
$$

Where, $\quad \mathrm{C}_{\mathrm{dl}}=$ double layer capacitance

$\mathrm{R}_{\mathrm{ct}}=$ Charge transfer resistance

$\mathrm{f}_{\max }=$ frequency at $Z$ " value maximum.

The inhibition efficiencies were obtained from $R_{c t}$ values as follows:

$$
\mathrm{IE} \%=\frac{\mathrm{R}_{\mathrm{ct}(\mathrm{i})}-\mathrm{R}_{\mathrm{ct}}}{\mathrm{R}_{\mathrm{ct}(\mathrm{i})}} \times 100
$$

Where, $\quad R_{c t}=$ Charge transfer resistance in the absence of inhibitor

$\mathrm{R}_{\mathrm{ct}(\mathrm{i})}=$ Charge transfer resistance in the presence of inhibitor.

Mild steel specimens (of $70 \mathrm{~mm}$ x $50 \mathrm{~mm} \times 1 \mathrm{~mm}$ ) coated with polymer were used for the fouling study. The study was carried out at the coast of Bay of Bengal in Chennai, on the East Coast of India. The specimens were suspended at a depth of $5 \mathrm{~m}$ from the lowest spring tide low water mark. The specimens hung vertically using nylon ropes with proper support in a protected area for 6 months. The specimens were removed and the distribution of fouling growth to observe the corrosion associated with fouling. The Streptomyces bacteria and A. Niger fungi have been used for in vitro antimicrobial activity.

\section{Spectral Characterization}

\section{RESULTS AND DISCUSSION}

A typical, ${ }^{13} \mathrm{C}-\mathrm{NMR}$ spectrum of MPTMACl-NTB copolymer is shown in Fig.-1. The ${ }^{13} \mathrm{C}-\mathrm{NMR}$ spectrum of MPTMACl-NTB copolymer shows the disappearance of vinyl carbon peaks at 121.76 and $138.89 \mathrm{ppm}$ of MPTMACl monomer. The spectrum shows the presence of a peak at $52.1 \mathrm{ppm}$, due to N$\mathrm{CH}_{3}$ group of MPTMACl unit. The peak at $28.37 \mathrm{ppm}$ is due to tert-butyl group of N-tert-butylacrylamide (BA) unit. The carbonyl carbon peaks appear at 163.53 and $174.54 \mathrm{ppm}$ are due to the BA and MPTMACl units respectively. The peak values confirm the formation of the copolymer.
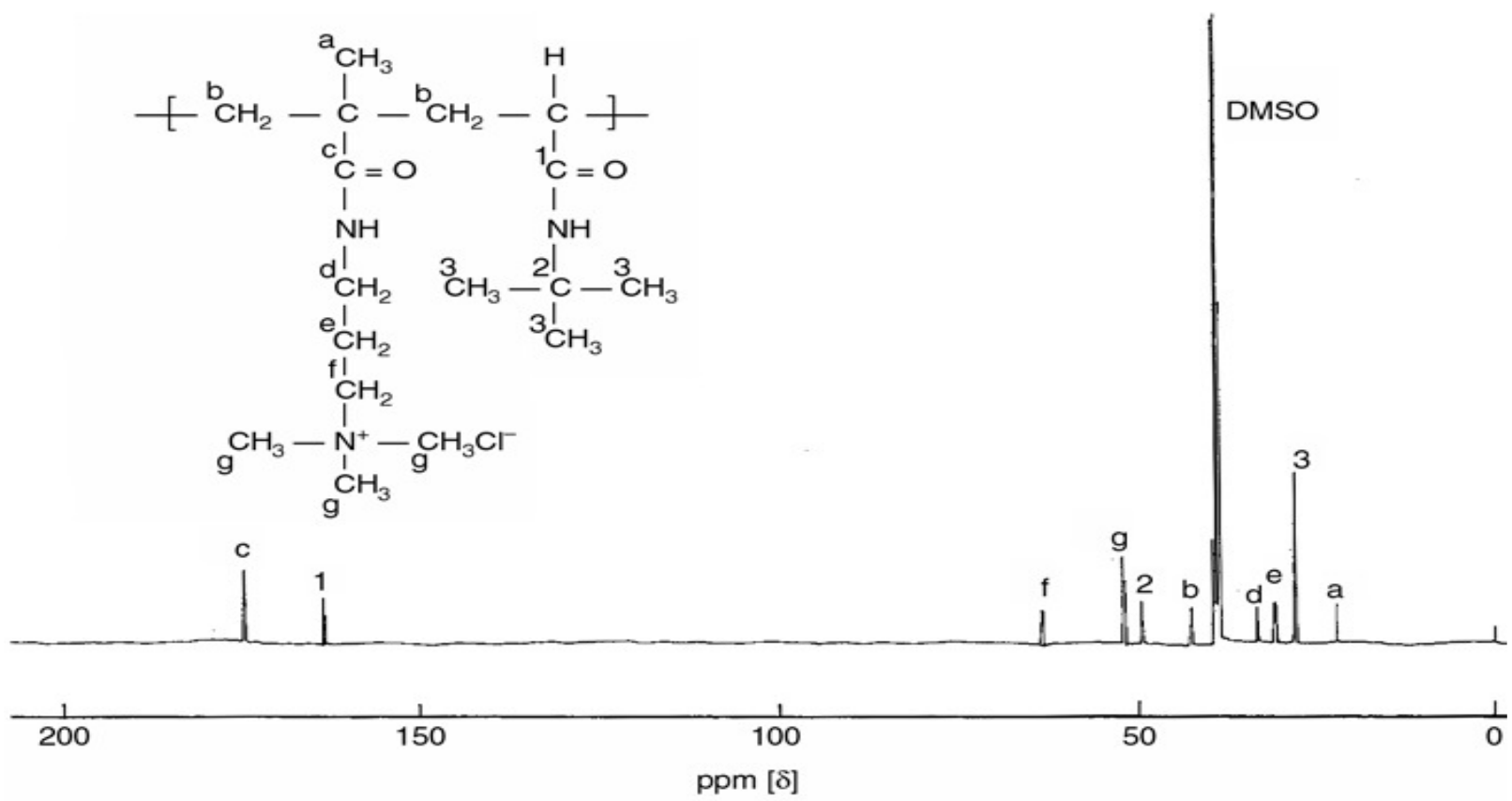

Fig. $-1:{ }^{13}$ C-NMR Spectrum of MPTMACl-NBA Copolymer 
RASĀYAN $J$. Chem.

Vol. 11 | No. 3 | 929 - 934 | July - September | 2018

\section{Thermal Analysis}

The TGA curve for MPTMA Cl-NTA copolymer are depicted in Fig.-2a and the thermogravimetric results are presented in the Table -2 . There are two stages of decomposition observed in the TGA spectrum, in which the thermal stability of copolymers was assessed by comparing the initial decomposition temperature (IDT). The initial decomposition temperature around $200^{\circ} \mathrm{C}$ was observed for these copolymers due to the moisture absorbed by them. The first and second stages of decomposition were occurred at $300^{\circ} \mathrm{C}$ and $400{ }^{\circ} \mathrm{C}$ respectively, further the final decomposition at $450^{\circ} \mathrm{C}$. Since the copolymers are stable up to $200^{\circ} \mathrm{C}$, it can be used as biomaterials. The SEM image (Fig.-2b) of MPTMACl-NTB indicates the surface morphology having nanosize particles.

Table -1: Potentiodynamic Polarization and Electrochemical Impedance Spectroscopy Studies of Ionomers on Mild Steel immersed in $\mathrm{NaCl}$

\begin{tabular}{|c|c|c|c|c|c|c|}
\hline \multirow[b]{2}{*}{ Coating System } & \multicolumn{3}{|c|}{ Potentiodynamic polarization } & \multicolumn{3}{|c|}{ EIS -Parameters } \\
\hline & $\begin{array}{l}E_{\text {Corr }} \\
(\mathrm{mv})\end{array}$ & $\begin{array}{c}\mathrm{I}_{\text {Corr }} \\
\mathrm{mA} / \mathrm{Cm}^{2}\end{array}$ & $\begin{array}{c}\text { Inhibition } \\
\text { Efficiency }(\%)\end{array}$ & $\begin{array}{c}\mathrm{R}_{\mathrm{ct}} \\
\left(\mathrm{ohm} \mathrm{cm} \mathrm{cm}^{2} \text { ) }\right.\end{array}$ & $\begin{array}{c}\mathrm{C}_{\mathrm{dl}} \\
\left(\mu \mathrm{F} \times 10^{-5}\right)\end{array}$ & $\begin{array}{c}\text { Inhibition } \\
\text { Efficiency } \\
(\%)\end{array}$ \\
\hline Blank & -670 & $\begin{array}{c}8.7757 \times 10^{-} \\
3\end{array}$ & --- & 47.03 & 6.373 & - \\
\hline $\begin{array}{l}\text { MPTMACl- } \\
\text { NTA } \\
\end{array}$ & -750 & $\begin{array}{c}1.8920 \times 10^{-} \\
3\end{array}$ & 78.4 & 126.3 & 5.814 & 62.7 \\
\hline $\begin{array}{l}\text { MPTMACl- } \\
\text { NTB }\end{array}$ & -620 & $8.066 \times 10^{-4}$ & 90.8 & 1283.0 & 3.723 & 96.3 \\
\hline $\begin{array}{l}\text { MPTMACl- } \\
\text { NCA }\end{array}$ & -600 & $1.327 \times 10^{-7}$ & 99.9 & 11820.0 & 2.345 & 99.6 \\
\hline
\end{tabular}

Table- 2: Thermal and Antimicrobial Studies of Ionomers

\begin{tabular}{c|c|c|c|c|c|c}
\hline \multirow{2}{*}{ Copolymers } & \multirow{2}{*}{$\begin{array}{c}\text { IDT } \\
\left({ }^{\circ} \mathrm{C}\right)\end{array}$} & $\mathrm{T}_{1}$ & $\left.\mathrm{~T}^{\circ} \mathrm{C}\right)$ & $\left({ }^{\circ} \mathrm{C}\right)$ & $\mathrm{T}_{\mathrm{f}}$ & \multicolumn{2}{|c}{ Antimicrobial activity } \\
\cline { 6 - 8 } & & & & & Streptomyces $(\mathrm{mm})$ & A. niger $(\mathrm{mm})$ \\
\hline MPTMA Cl-NTA & 115 & 300 & 400 & 450 & 2.2 & - \\
\hline MPTMA Cl-NTB & 145 & 310 & 410 & 450 & 3.0 & - \\
\hline MPTMA Cl-NCA & 150 & 310 & 420 & 450 & 4.5 & 10 \\
\hline
\end{tabular}

IDT - Initial decomposition temperature; $\mathrm{T}_{1}-$ Decomposition temperature in Stage- 1

$\mathrm{T}_{2}$ - Decomposition temperature in Stage $-2 ; \mathrm{T}_{\mathrm{f}}-$ Final decomposition temperature

\section{Corrosion Studies}

The various polarization parameters such as corrosion current $\left(\mathrm{I}_{\text {corr }}\right)$, corrosion potential $\left(\mathrm{E}_{\text {corr }}\right)$, anodic and cathodic Tafel slopes were derived from potentiostatic polarization studies on mild steel in $3.5 \% \mathrm{NaCl}$ solution. The results of the experiments in the presence and absence of different inhibitors like MPTMACl-NTA, MPTMACl-NTB and MPTMACl-NCA at an optimum concentration at room temperature are shown in Fig.-2c and the corresponding polarization parameters are given in Table-1 .It can be noticed that the polymer causes a decrease in the corrosion rate i.e. shifts both anodic and cathodic curves to lower values of current densities as compared to the blank. Moreover, these results indicate the polymer acts as a mixed type of corrosion protection. The $\mathrm{I}_{\text {corr }}$ values are decreases in the order of NTA,NTB and NCA containing ionomers and thereby IE\% values are increases with the same order. The increase of inhibition efficiency (IE) due to a blocked fraction of the electrode surface by adsorption.NCA containing copolymer showed maximum inhibition efficiency of $99.9 \%$. Therefore NCA containing ionomer form more stable and perfect film on the steel Surface ${ }^{14}$.

The electrochemical impedance plots (Nyquist) for uncoated and coated (MPTMACl-NTA,MPTMAClNTB and MPTMACl-NCA copolymers) on mild steel at $3.5 \% \mathrm{NaCl}$ are illustrated in Fig.-2d. The semicircle area attributed to charge transfer resistance $\left(\mathrm{R}_{\mathrm{ct}}\right)$ increases with increasing order of NTA,NTB and NCA containing copolymer coating, which resists the penetration of $\mathrm{NaCl}^{15}$. The $\mathrm{C}_{\mathrm{dl}}$ value decreases 
RASĀYAN J. Chem.

Vol. 11 | No. 3 |929 - 934 | July - September | 2018

on increasing the addition of different inhibitor at an optimum concentration and reaches very low value for the optimum concentration of all the studied system indicating that the reduction of charge accumulated in the double layer due to the formation of adsorbed inhibitor layer.
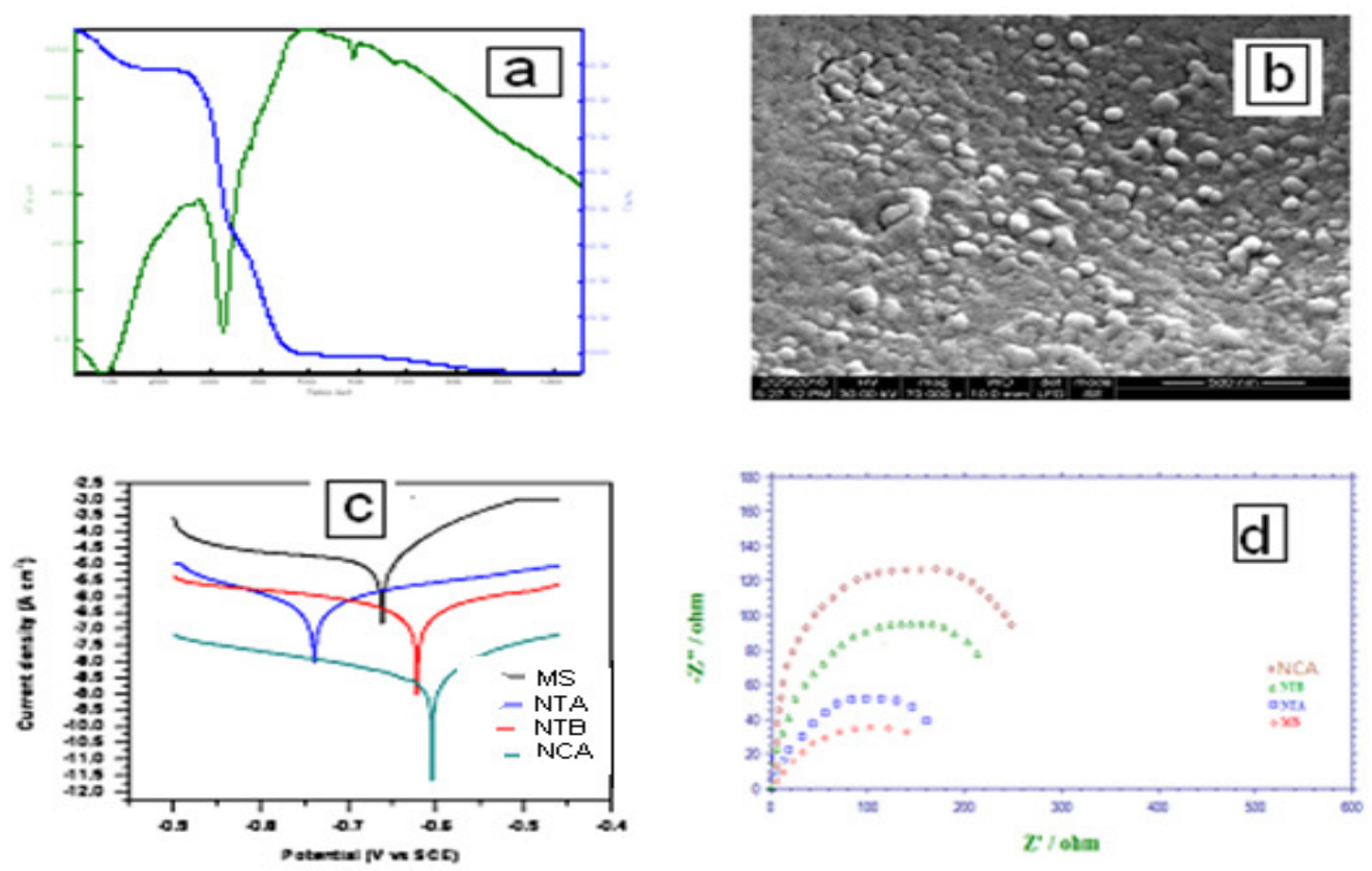

Fig.-2: Thermogravimetric Analysis (a) ,SEM image(b) , Potentiodynamic Polarization (c)Electrochemical Impedance Spectroscopy (d) Studies of Ionomers
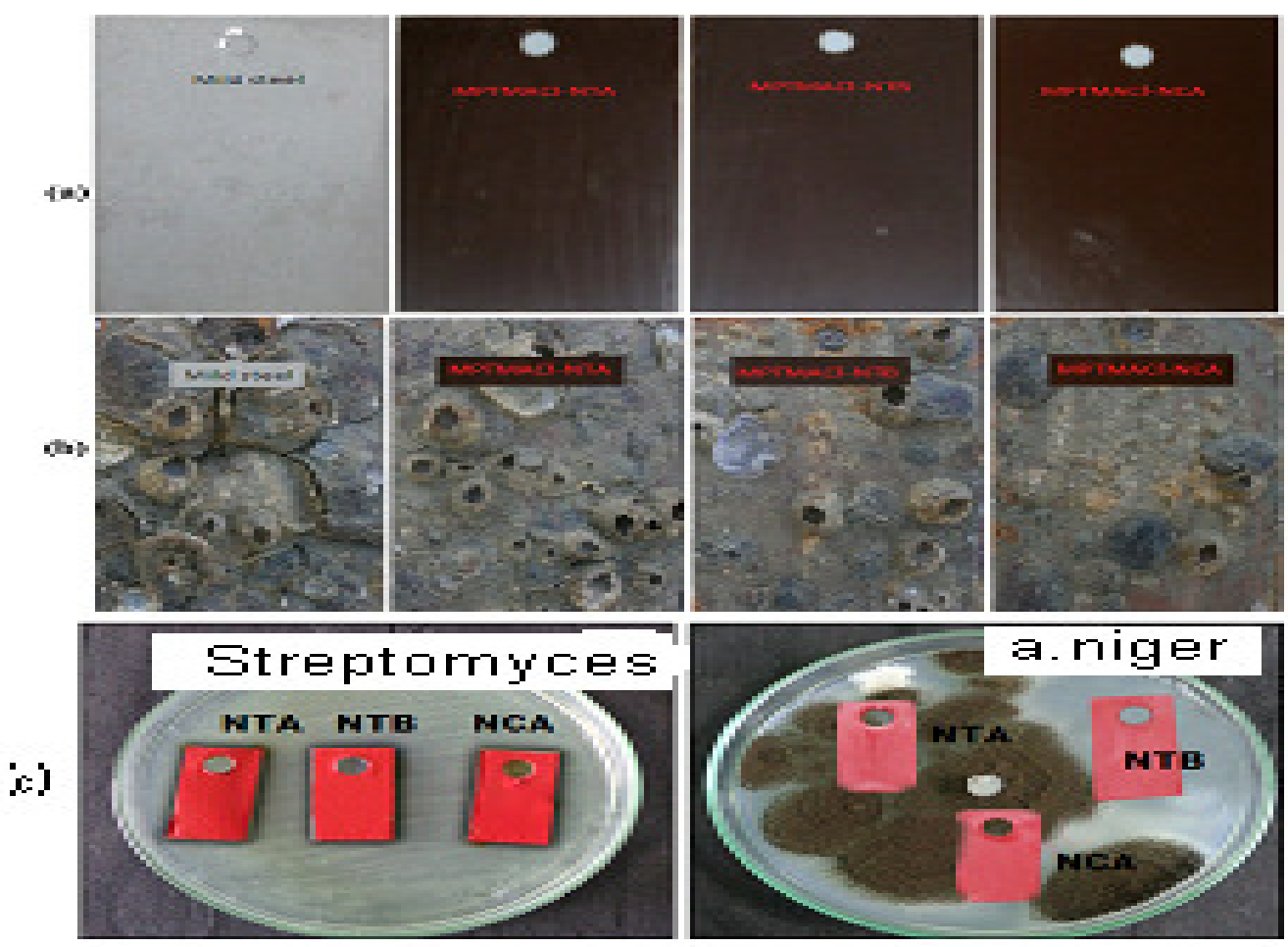

Fig. -3: Antifouling (a) Before Immersion (b) After Immersion and (c) Antimicrobial Studies of Ionomers 933 
RASĀYAN J. Chem.

Vol. 11 | No. 3 |929 - 934 | July - September | 2018

The MPTMACl-NCA showed a maximum of $99.6 \%$ inhibition .Both the potentiodynamic polarization and Electrochemical impedance spectroscopic methods showed almost the same corrosion resistance. These results indicated that MPTMACl-NCA ionomer effectively prevents the penetration of corrosive ions.

\section{Antimicrobial Studies}

The antifouling and antimicrobial activity of Ionomers are shown in Fig.-3 and are given in Table-2. Among all copolymers, MPTMACl-NCA copolymer showed more inhibition against selected microorganisms. From the fouling study, we can observe that the intensity of fouling organisms was minimum on MPTMACl-NCA containing panel.

\section{CONCLUSION}

Copolymers of MPTMACl with N-substituted acrylamide were synthesized in aqueous methanol at $55 \pm 0.1^{\circ} \mathrm{C}$ using ACVA as an initiator. The synthesized copolymers were confirmed by ${ }^{13} \mathrm{C}-\mathrm{NMR}$ spectroscopy. TGA analysis indicates that copolymers undergo double stage decomposition and are stable up to $200^{\circ} \mathrm{C}$, therefore it can be used as biomaterials. The SEM analysis of copolymer showed a nanosize microstructure surface. The corrosion inhibition studies in $\mathrm{NaCl}$ medium showed NCA containing Ionomers exhibits 99\% inhibition efficiency. Inhibition efficiencies obtained from potentiodynamic polarization curves and EIS are in good agreement. These synthesized ionomers showed both antimicrobial and antifouling activity.

\section{REFERENCES}

1. V. S. Saji and J. Thomas, Curr. Sci., 92(1), 51 (2007)

2. R. E. Hameed, H. I. AL Shafey, S. A. Soliman, M. S. Metwally and Al-Azhar, Bull. Sci., 19, 283 (2008).

3. R.S. Abdel Hameed, H.I. Al Shafey, E.A. Ismail, Al-Azhar, Bull. Sci., 20 (1), 185 (2009)

4. H. A. Shehata, H. M. Abdelbary, S. A. Soliman, A. M. Salem, A. M. Atta and R. A. Hameed, Mat. Sci., 8,289 (2012).

5. R.S. Abdel Hameed, Adv. in Appl. Sci.Res., 2, 483 (2011).

6. R. S. Abd El Hameed, H.I. AL-Shafey, and O. A. Farghaly, Res.and Rev.in Electrochem.,3,41( 2012)

7. R. S. Abd El Hameed, Journal of Phy. Chem., 117 (6), 1069 (2013).

8. R.S. Abdel Hameed, Portugaliea Electrochimica Acta., 29,273 (2011).

9. S.A. Umoren, The Open Corr. J., 2, 175 (2009) .

10. M. M. Solomon and S. A. Umoren, J. of Adh. Sci. and Techn., 29,1060 ( 2015)

11. I. L. Lehr and S. B. Saidman, Electrochim. Acta., 51,3249 (2006), DOI :10.1016/j.electacta.2005.09.017.

12. H. Plaut and J.J. Ritter, J. Am. Chem. Soc., 73,4076 (1951).

13. P. Saravanan, S. Aparna, S. Ananda Kumar and D. Duraibabu, Curr. Bionanotech., 1(1), 37 (2015).

14. A.M.Atta,G.A.El-Mahdy,H.A.Al-lohedan,A.M.Tawfeek and S.R.Sayad, Int. J. Electrochem. Sci.,10, 2377 (2015).

15. S. Skale, D. Dolecek and M. Slemnik, Corr. Sci.,49,1045 (2007), DOI:10.1016/j.corsci.2006.06.027

[RJC-2073/2018] 